\title{
Changes of Homologue Profiles of PCDD/Fs in Waste Incineration in a Laboratory-Scale Fluidized-Bed Reactor
}

\author{
Takeshi HATANAKA, Akio KITAJIMA, and Masao TAKEUCHI
}

(Received January 16, 2002)

\section{小型流動層を用いた廃棄物燃焼に伴う排ガス中ダイオキシン類の同族体分布の変化 畑中健志, 北島暁雄, 竹内正雄}

\begin{abstract}
Combustion experiments using a laboratory-scale fluidized-bed reactor were performed to elucidate the influence of chlorine content in wastes and combustion temperature on homologue profiles of polychlorinated dibenzo- $p$-dioxins and dibenzofurans $(\mathrm{PCDD} / \mathrm{Fs}$ ) during incineration of model wastes with polyvinyl chloride or sodium chloride as a chlorine source and copper chloride as a catalyst. The experimental setup was carefully planned to obtain reliable data. In all experiments, the higher ratio of chlorination of PCDDs to PCDFs was obtained. As CO concentration in flue gas increased, the amount of $\mathrm{PCDD} / \mathrm{Fs}$ increased and their homologue profiles were shifted toward higher chlorinated species. Such trends were more significant in PCDFs than PCDDs. The changes of the homologue profiles show that the major formation pathways are different between PCDDs and PCDFs. PCDDs could mainly form via materials that readily react with chlorine. The major formation pathways of PCDFs are strongly affected by combustion conditions.
\end{abstract}

\section{Key Words}

Homologue profile, PCDD/Fs, Combustion condition, Model waste incineration

\section{1. 緒 言}

主に廃棄物焼却に伴って排出されているダイオキシン類は, 微量でも生体への強い影響があると考えられており，その排 出量を減らすために多大な努力が続けられている。すでに大 型焼却炬に対する対策技術はかなり進んでおり，新鋭大型焼 却炉から排出される排煙中のダイオキシン類は，コストは別 として現在の法規制に比べても低レベルに抑えられるように なってきた。しかし, 中小型焼却炉では大型炉と同等の排出 抑制対策を行うことは技術的にもコスト面でも困難であり， さらなる低減化への強い要求がある。また，工業炉など焼却 炉以外からの排出も現状では割合は低いものの無視できない 量であり，焼却炉に比べて対策は一段と困難と考えられる。 燃焼に起因するダイオキシン類の確実な排出抑制の実現には, 生成機構を解明し，その理解に基づいて対策技術を確立する ことが極めて重要である。

ダイオキシン類の生成挙動に影響を及ぼす要因としては, 廃棄物に含まれる塩素源や金属成分，炉内の燃焼状態などが 考えられ，実機や実験室規模の装置を用いてさまざまな調

Institute for Energy Utilization, National Institute of Advanced Industrial Science and Technology, 16-1 Onogawa, Tsukuba-shi, Ibaraki 305-8569, Japan
査・研究が行われている ${ }^{122)}$ 。これらの要因はダイオキシン類 の生成量に影響を及ぼすだけでなく，ダイオキシン類の生成 挙動を考える上で重要な指標である同族体分布にも影響を及 ぼすことが分かってきた。例えば，ダイオキシン類の生成触 媒となる塩化銅が廃棄物中に存在すると，燃焼に伴い生成さ れるポリ塩化ジベンゾパラダイオキシン (PCDDs) やポリ塩 化ジベンゾフラン (PCDFs) の同族体分布が高塩化物側に移 行する ${ }^{3)}$ )。これは触媒成分による塩素化の働きと深く関係し ている ${ }^{5)}$ ）。また，炬内の燃焼状態が生成する PCDD/Fs など 有機塩素化合物の塩素化の度合いに影響することも報告され ている ${ }^{8)}{ }^{9)}$ 。今川ら ${ }^{10)}$ は，実際の焼却施設から排出される $\mathrm{PCDD} / \mathrm{Fs}$ の同族体分布を調べて，炉の形状によって特徵的な 分布が現れることを明らかにした。このようにダイオキシン 類の同族体分布はその生成過程と密接に関係しているが，同 族体分布の変化に関する系統的な研究は行われておらず，ど のような因子が同族体分布に影響を与えるかについては未だ 未解明の部分が多い。同族体分布に影響を与える要因につい て検討することは，ダイオキシン類の生成機構を解明する上

産業技術総合研究所 エネルギー利用研究部門

干 305-8569 茨城県つくば市小野川 $16-1$ 
で非常に重要である。

本研究では，廃棄物に含まれる塩素量と燃焼室の温度が $\mathrm{PCDD} / \mathrm{Fs}$ の同族体分布に与える影響を明らかにし，これらの 結果に基づいて PCDD/Fs の生成機構に関して知見を得るこ とを目的とする。筆者らはこれまでに, 廃棄物の塩素含有量 や燃焼室の温度が PCDD/Fs 生成量に及ぼす影響について明 らかにした ${ }^{112)}$ 。これらの研究では, 目的とする因子の影響 について精度の高い結果を得るために, 外熱式の小型流動層 実験装置を用いて模擬ゴミの燃焼実験を行った。この実験で は, 装置内燃焼条件の空間的，時間的不均一性を最小限に抑 えるために，外熱式の小型燃焼装置を用いた。また，前回行 った実験の影響が現れないように，後述の通り装置と条件を 整えて燃焼実験を行った。本報では，このように細心の注意 を払って行った燃焼実験の排ガス中 PCDD/Fs の同族体分布 を比較・検討することにより，ダイオキシン類の同族体分布 に影響を与える要因について検討する。また，この結果に基 づきダイオキシン類の生成挙動に関して考察する。

\section{2. 実験装置と方法}

実験装置の概略図を Fig. 1 に示す。この装置は一次燃焼室, 二次燃焼室, 冷却部から構成される。一次燃焼室は石英製の 流動層燃焼装置（申60 mm $\times 300 \mathrm{~mm} ）$ であり，流動媒体とし て珪砂 $(100 \sim 140 \mu \mathrm{m})$ を使い，静止層高は $100 \mathrm{~mm}$ とした。 二次燃焼室は内径 $30 \mathrm{~mm}$ ，高さ $1,450 \mathrm{~mm}$ の石英の直管である。 これらの燃焼室は, 所定の温度になるように電気炉により加 熱した。冷却部は内径 $30 \mathrm{~mm}$, 長さ $300 \mathrm{~mm}$ のガラス管 3 本を 直列に接続し，ヒーターにより一定温度に加熱した。冷却部 を通過した排ガスは連続ガス分析計に入り, 一酸化炭素 $(\mathrm{CO})$, 二酸化炭素 $\left(\mathrm{CO}_{2}\right)$, 酸素 $\left(\mathrm{O}_{2}\right)$ の濃度がそれぞれ連続的に測 定・記録される。模擬ゴミは流動層の上部からスクリューフ イーダを用いて供給した。

排ガスの PCDD/Fs 濃度測定のためのサンプリングは, 実 験装置内の燃焼状態がほぼ一定になった後, 冷却部中間点 $(\mathrm{X})$ から 4 時間以上かけて行った。排ガス中の固形分はグラスウ ールフィルターに捕集し，トルエンによるソックスレー抽出 を 24 時間行った。気相部分は氷冷した捕集管とフロリジル吸 着剤により捕集した。捕集液はへキサンにより抽出した。これ らの抽出液はシリカゲルカラムと活性炭カラムにより精製し, 濃縮処理を施してから,ガスクロマトグラフ質量分析計（日立 M-80B またはJEOL JMS-700)により同定・定量を行った。

本研究では同族体分布の変化を詳細に検討するため, 精度 の高い実験デー夕を得ることが重要である。そのため実廃棄 物の代わりに, 組成が明確かつ均一になるように調整した模 擬ゴミを用いた。無漂白パルプ $45 \mathrm{wt} \%$ ，小麦粉 $40 \mathrm{wt} \%$ ，木粉 $15 \mathrm{wt} \%$ をべースとし，これに塩素源や触媒成分を加え，粉 砕・混合して $1 \sim 3 \mathrm{~mm}$ の粒子状に成形した ${ }^{11}$ 。塩素源として ポリ塩化ビニル (PVC, 重合度 $\fallingdotseq 1,100$, 和光純薬) または塩 化ナトリウム $(\mathrm{NaCl}$, 和光純薬) を用いた。各模擬ゴミの塩 素源と塩素含有率を Table 1 に示す。触媒成分として, 模擬ゴ ミすべてに塩化銅 $\left(\mathrm{CuCl}_{2} \cdot 2 \mathrm{H}_{2} \mathrm{O}\right.$, 和光純薬 $)$ を $0.25 \mathrm{wt} \%$ にな

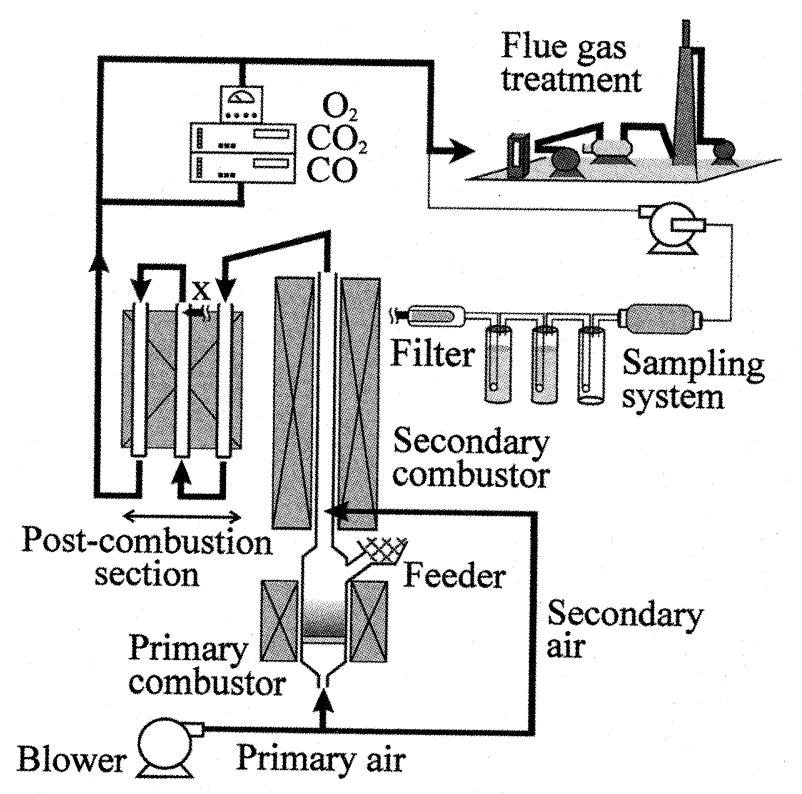

Fig. 1 Schematic diagram of experimental setup

Table $1 \mathrm{Cl}$ contents in artificial solid wastes *

\begin{tabular}{ccc}
\hline Fuel No. & Cl source & Cl contents [\%] \\
1) Effects of $\mathrm{Cl}$ contents in wastes & \\
1 & PVC & 0.18 \\
2 & PVC & 0.45 \\
3 & PVC & 0.64 \\
4 & PVC & 1.24 \\
2) Effects of temperatures of combustion zones & \\
A & $\mathrm{NaCl}$ & 0.48 \\
$\mathrm{~B}$ & $\mathrm{PVC}$ & 0.45 \\
\hline
\end{tabular}

* All wastes contain $0.25 \% \mathrm{CuCl}_{2} \cdot 2 \mathrm{H}_{2} \mathrm{O}$.

るように添加した。作製した試料量の関係で，塩素源として $\mathrm{PVC}$ と $\mathrm{NaCl}$ の両方を用いたが, 燃焼室の温度が $900{ }^{\circ} \mathrm{C}$ の場 合, $\mathrm{PVC}$ と $\mathrm{NaCl}$ を用いた場合の $\mathrm{PCDD} / \mathrm{Fs}$ の生成挙動に大き

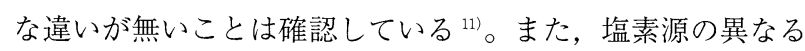
模擬ゴミを用いた実験の結果は直接比較しなかった。実験を 行う際には，実験順序の影響が現れないように，実験に用い るすべての石英, ガラス管を洗浄, もしくは新しい部品と取 り替えて使用した。特に一次燃焼室は，ほとんどの場合新し い部品と取り替えた。流動媒体には新しい珪砂を用い, 試料 供給装置も実験毎に洗浄した。

\section{3. 実験結果と考察}

\section{1 塩素含有量の同族体分布への影響}

模擬ゴミの塩素含有量の影響を調べた一連の実験条件を Table 2 に示す。空気比 $(\lambda)$ は全体で 2.0 とした。模擬ゴミに は塩素源として PVCを含んだFuel 1〜4を用いた。Fuel 2 （塩素含有率 $0.45 \%$ ）の燃焼実験で得られた PCDDs (T4CDDs $\sim \mathrm{O} 8 \mathrm{CDD})$ と PCDFs (T4CDFs 〜 O8CDF) の同族体分布を Fig. 2 に示す。模擬ゴミに添加した塩化銅は塩素化を促進する活性の 高い触媒であり,塩素含有量が同じでも塩化銅を添加した模擬 ゴミを燃焼すると, $\mathrm{PCDD} / \mathrm{Fs}$ 生成量が増加するとともに同族 
Table 2 Experimental conditions

\begin{tabular}{ll}
\hline Temperature $\left[{ }^{\circ} \mathrm{C}\right]$ & \\
Primary combustion zone & 900 \\
Secondary combustion zone & 900 \\
$\quad$ Post-combustion section & 350 \\
Flow rate $\left[\mathrm{m}^{3} \mathrm{~N} / \mathrm{h}\right]$ & \\
$\quad$ Primary air & $0.46(\lambda=1.3)$ \\
Secondary air & $0.26(\lambda=0.7)$ \\
Fuel feed rate $[\mathrm{g} / \mathrm{h}]$ & 100 \\
\hline
\end{tabular}

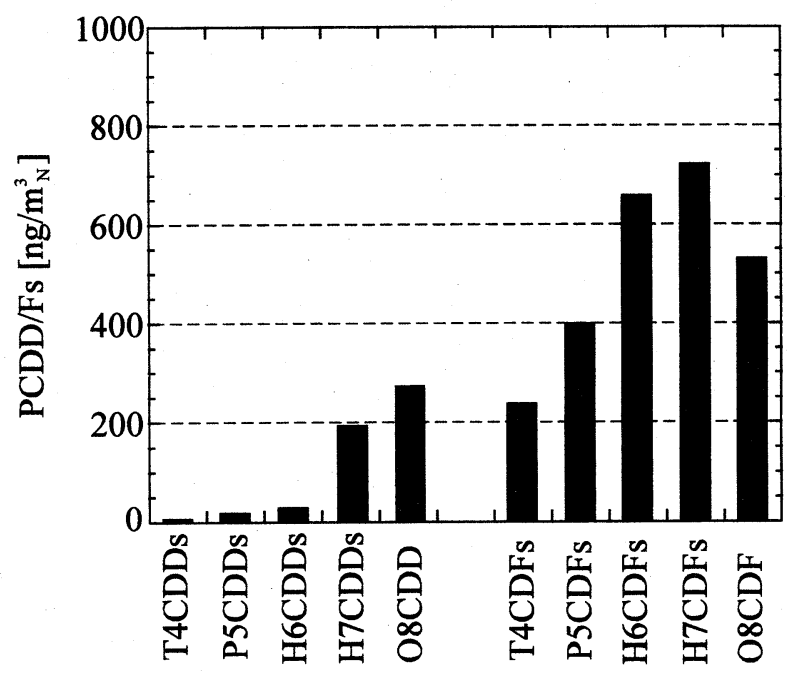

Fig. 2 Homologue profiles of PCDD/Fs obtained by the experiment using Fuel 2

体分布が高塩化物側に移行する傾向がある ${ }^{3)}{ }^{4)}$ 。実際に Fuel 4 (塩素含有率 1.24\%) の場合には, PCDDs, PCDFs の双方とも 高塩化物が多く生成した。しかし塩素含有率が少ない Fuel 2 では, PCDFs で異なる傾向が現れ, 八塩化物の量が七塩化物よ り少なくなった。今回用いた模擬ゴミの塩化銅含有量は, 塩素 化触媒としての役割を果たすには十分な量であるが4), PCDFs では高塩化物ほど多く生成している訳ではないことは興味深 い事実である。そこで模擬ゴミの塩素含有量が PCDD/Fs の同 族体分布に及ぼす影響について詳細に検討する。

Fig. 3 (a) にT4CDDs から O8CDD までの生成量全体に対す る各同族体の割合を示す。どの実験結果でも高塩化物ほど割 合が多くなっているが, 模擬ゴミの塩素含有率が高くなるに したがって高塩化物がより多く生成し, PCDDsの塩素化が進 んでいる。例えば八塩化物の割合は Fuel 1 で 37\%, Fuel 4 で は $76 \%$ と約 2 倍になっている。次に PCDFs について同様の 図を Fig. 3 (b) に示す。ここでも塩素含有率が高くなるにした がって高塩化物が多く生成している。Fuel 1 では四塩化物と 八塩化物が若干少ないが, 各同族体の割合に大きな違いはな い。これが Fuel 2，3 と塩素含有率が高くなるにつれて，低塩 化物が減少し，八塩化物が増えている。Fuel 4 では四塩化物 が $1 \%$ 以下，八塩化物が $63 \%$ と圧倒的に高塩化物が多くなる。 一方, PCDDs と PCDFs の結果を比較すると，すべての実験 で PCDFs に比べて PCDDs の方が塩素化が進んでいることが 分かる。また模擬ゴミの塩素含有率が増加した時, PCDDsに比

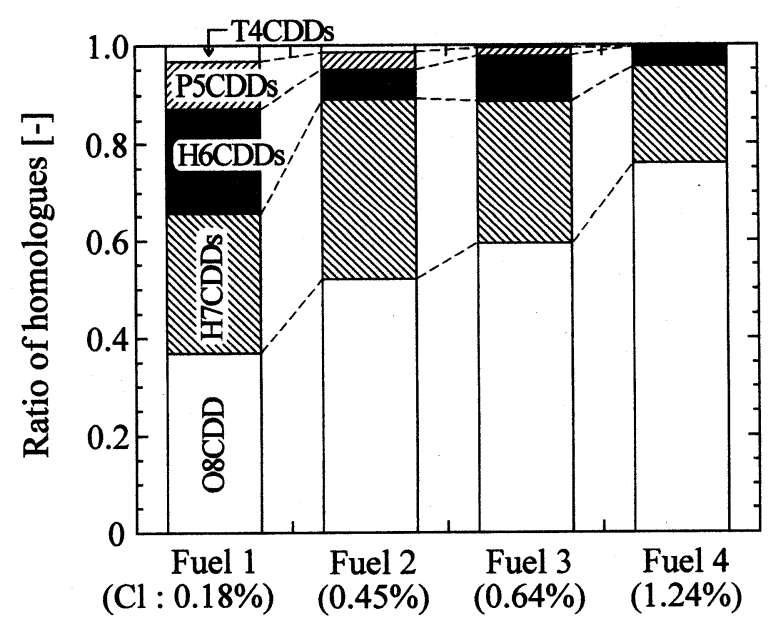

(a) PCDDs

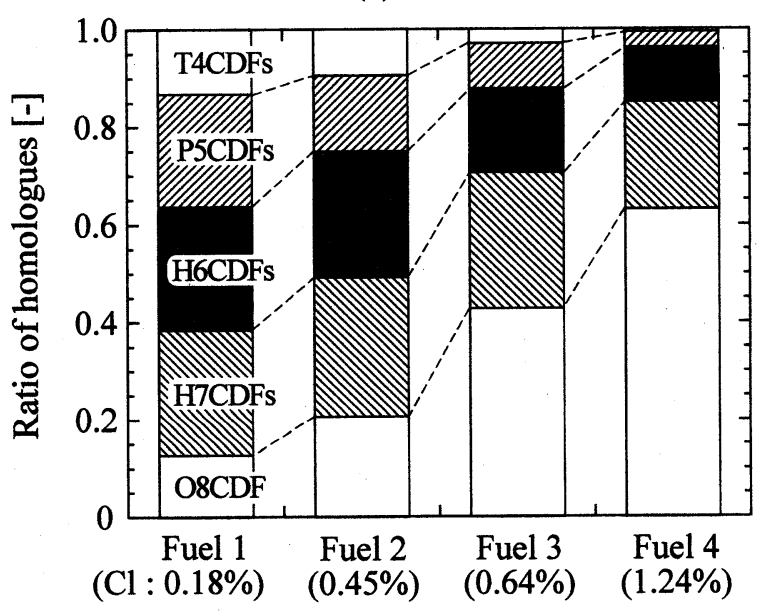

(b) PCDFs

Fig. 3 Changes of homologue profiles of PCDD/Fs in the experiments with changes in the chlorine content in model wastes

ベて PCDFs の方が塩素化の進み方が大きく変化している。例 えば八塩化物の割合に注目して Fuel 1 と Fuel 4 を比較すると, PCDDs では約 2 倍, PCDFs では約 5 倍となっている。さらに, 四塩化物から八塩化物までの合計濃度を PCDDs と PCDFs そ れぞれについて求め, その合計濃度と PCDFs に対する PCDDs の生成量比とを Fig. 4 に示す。PCDD/Fs 生成量は塩素含有率 の上昇とともに増加するが, 生成量比は低下しており, PCDFs の方が増加量が多いことを示している。したがって塩素含有 率が低い場合には PCDDsの生成が相対的に重要になる。

\section{2 燃焼室温度の同族体分布への影響}

前述の通り模擬ゴミの塩素含有率を変えた実験では, 塩素 含有率が高くなるにつれて PCDD/Fs 生成量が増加するとと もに，同族体分布が高塩化物側に移行する傾向が明確に現れ た。この原因としては, 模擬ゴミの塩素含有率の増加により, $\mathrm{PCDD} / \mathrm{Fs}$ 生成に関わる塩素量が増えたことが考えられる。す なわち, 反応場の塩素濃度の上昇により塩素化の機会が増し, 結果として高塩化物の増加となって表れたことが考えられる。 一方，これらの実験では，塩素含有率が高くなると排ガスの 


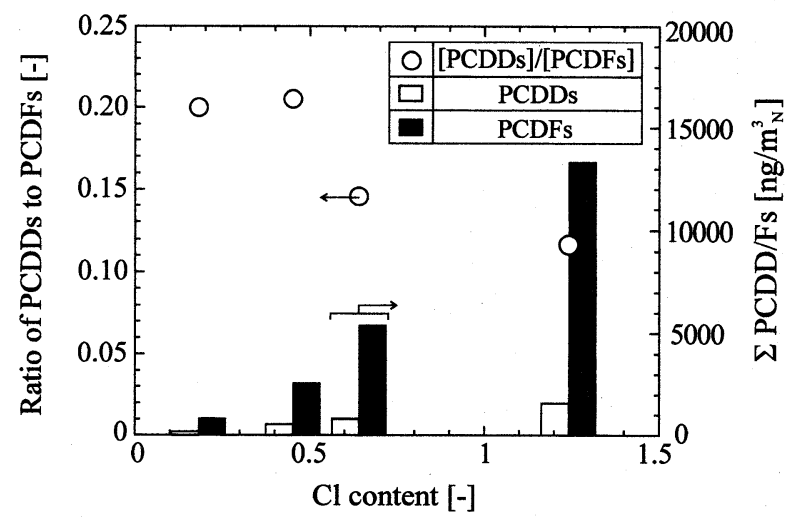

Fig. 4 PCDD/Fs concentrations and their ratio obtained by changing the chlorine content in model wastes

$\mathrm{CO}$ 濃度も高くなった。炉内の燃焼反応の変化は生成する $\mathrm{CO}$ 濃度を変え, $\mathrm{PCDD} / \mathrm{Fs}$ 生成量にも大きな影響を与えることが 分かっている ${ }^{11}$ 。以上のことから, Fig. 3 で観察された同族体 分布の変化は, 反応に関わる塩素量の変化だけが原因ではな く, 模擬ゴミ中の塩素量の変化に伴う燃焼反応の変化に起因 するとも考えられる。そこで模擬ゴミ中の塩素量の影響を受 けないように，燃焼実験を同一組成の模擬ゴミについて，燃 焼室の温度だけを変えて行った場合の同族体分布の変化につ いて検討する。

Fig. 5 に二次燃焼室の温度を変えて行った燃焼実験で得られ た $\mathrm{PCDD} / \mathrm{Fs}$ の各同族体の割合を示す。一次燃焼室の温度は $700{ }^{\circ} \mathrm{C}$ と, 二次燃焼室の温度を $700{ }^{\circ} \mathrm{C}$ と $900{ }^{\circ} \mathrm{C}$ に設定した場 合の結果を比較した。その他の実験条件は Table 2 と同じであ る。模擬ゴミにはFuel A を用いた。塩素含有率を変えた場合 と同様, PCDDsの方が高塩化物が多く, PCDFs より塩素化が 進んでいる。また二次燃焼室の温度が上昇すると, 排ガスの $\mathrm{CO}$ 濃度は大幅に低下し, それに伴って PCDD/Fs 生成量も減 少するが 12)，この時 Fig. 5 に示す通り高塩化物の割合も少なく なっている。一方, PCDFs に対する PCDDs の生成量比は大 きくなっている (Table 3)。次に二次燃焼室の温度を $900{ }^{\circ} \mathrm{C}$ と し, 一次燃焼室の温度を $700{ }^{\circ} \mathrm{C}$ と $900{ }^{\circ} \mathrm{C}$ に設定した場合の結 果を Fig. 6 に示す。模擬ゴミには Fuel B を用いた。同族体の 割合を見ると, Fig. 5 と同じく PCDDs の方が塩素化が進んで いる。また一次燃焼室の温度を上げると, 排ガスの CO 濃度 とともに PCDD/Fs 生成量が増加するが12)，この時 Fig. 6 に示 す通り高塩化物の割合も増加している。一方，PCDFs に対す る PCDDs の生成量比は小さくなっている（Table 4)。つまり, $\mathrm{CO}$ 濃度と $\mathrm{PCDD} / \mathrm{Fs}$ 生成量の減少に伴って高塩化物の割合が 少なくなり，PCDFsに対する PCDDs の生成量比は大きくな っている。これは，上述した二次燃焼室の温度を変えた場合 と同様の傾向である。一連の実験では, 同一の模擬ゴミを同 じ速度で供給しているため, 供給した塩素量は同じであり, $\mathrm{PCDD} / \mathrm{Fs}$ 生成に関わる塩素量は $700{ }^{\circ} \mathrm{C}$ の場合と $900{ }^{\circ} \mathrm{C}$ の場合 で大きな違いはないと推定できる。また, 塩素化の機構につ いては明確になっていないが，一次燃焼室と二次燃焼室で塩 素化の機構が同じと仮定すると, 温度上昇とともに一次燃焼

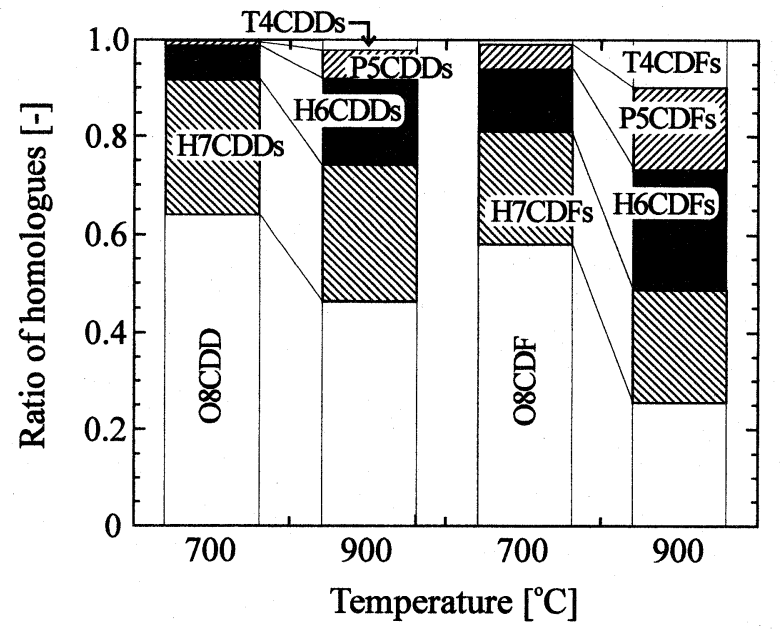

Fig. 5 Changes of homologue profiles obtained by changing the temperature of the secondary combustion zone. (The temperature of the primary combustion zone is $700{ }^{\circ} \mathrm{C}$.)

Table 3 Results of the experiments on the effects of the temperature of the secondary combustion zone *

\begin{tabular}{lrr}
\hline $\begin{array}{l}\text { Temperature of the secondary } \\
\text { combustion zone }\left[{ }^{\circ} \mathrm{C}\right]\end{array}$ & 700 & 900 \\
\hline CO $[\mathrm{ppm}]$ & 2,700 & 27 \\
PCDDs $\left[\mathrm{ng} / \mathrm{m}^{3} \mathrm{~N}\right]$ & 2,300 & 130 \\
PCDFs $\left[\mathrm{ng} / \mathrm{m}^{3} \mathrm{~N}\right]$ & 26,000 & 480 \\
Ratio of PCDDs to PCDFs [- $]$ & 0.09 & 0.27 \\
\hline
\end{tabular}

* The temperature of the primary combustion zone is $700{ }^{\circ} \mathrm{C}$.

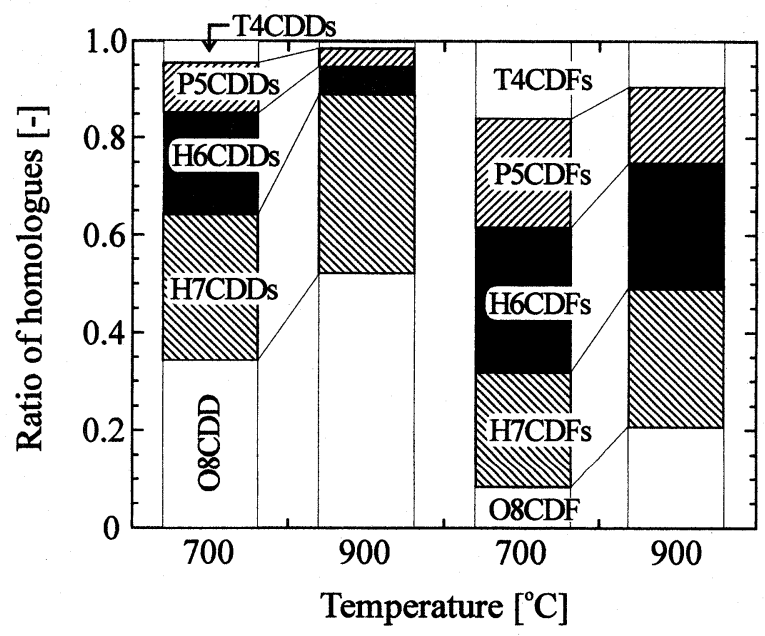

Fig. 6 Changes of homologue profiles obtained for the different temperature of the primary combustion zone. (The temperature of the secondary combustion zone is $900^{\circ} \mathrm{C}$.)

Table 4 Results of the experiments on the effects of the temperature of the primary combustion zone *

\begin{tabular}{lrr}
\hline $\begin{array}{l}\text { Temperature of the primary } \\
\text { combustion zone }\left[{ }^{\circ} \mathrm{C}\right]\end{array}$ & 700 & 900 \\
\hline $\mathrm{CO}[\mathrm{ppm}]$ & 14 & 64 \\
$\mathrm{PCDDs}\left[\mathrm{ng} / \mathrm{m}^{3} \mathrm{~N}\right]$ & 32 & 520 \\
$\mathrm{PCDFs}\left[\mathrm{ng} / \mathrm{m}^{3} \mathrm{~N}\right]$ & 130 & 2,600 \\
Ratio of PCDDs to PCDFs [-] & 0.24 & 0.20 \\
\hline
\end{tabular}

* The temperature of the secondary combustion zone is $900{ }^{\circ} \mathrm{C}$ 
室の場合には高塩化物側に移行し, 二次燃焼室の場合には低 塩化物側に移行したことを考えると, 本実験条件下では, 温 度による塩化速度の違いが同族体分布の塩素化の度合いに与 える影響は比較的小さいと考えられる。

以上の実験結果において, 排ガスの $\mathrm{CO}$ 濃度と $\mathrm{PCDD} / \mathrm{Fs}$ 生 成量が正の相関を示し，これらの変化と同時に同族体分布も 変化していることを考えると, 燃焼反応が PCDD/Fs 生成挙 動に大きな影響を及ぼしていることは確かである。このこと を踏まえて前述した模擬ゴミの塩素含有率を変えた実験の結 果を再考すると, 模擬ゴミ中の塩素は塩化反応に関与するだ けでなく, 燃焼反応にも影響を与え, その結果 PCDD/Fsの 生成量, 同族体分布が変化したと言える。

\section{3 生成機構について}

上述の実験では, PCDDsの方が PCDFsに比べて塩素化が 進んでいた。また排ガスのCO濃度が増えると, PCDDs, $\mathrm{PCDFs}$ ともに生成量が増加し, 同族体分布は高塩化物側に移 行した。この生成量と同族体分布の変化は PCDFs の方が PCDDs に比べて大きかった。この結果は, 本実験条件下では PCDDs と PCDFs の主要な生成機構が異なることを示してい ると考えられる。すなわち, PCDDs と PCDFs の生成挙動の 違いを, 単純にジベンゾパラダイオキシンやジベンゾフラン の塩素化や $\mathrm{PCDD} / \mathrm{FS}$ の塩素化・脱塩素化の違いのみによっ て説明することは難しい。

燃焼過程でのダイオキシン類の生成経路として主に2つの 経路が考えられている。ダイオキシン類と構造が近いクロロ フェノールやクロロベンゼンなどの前駆物質が縮合して生成 する場合と，すすや未燃炭素などの分解に伴って生成する場 合である ${ }^{13)}$ 。ここで以下の 2 つ仮定をおく。

1）すすや未燃炭素などの分解に伴って PCDD/Fs が生成 する際の塩化速度は, 前駆物質の塩化速度より遅いが, $\mathrm{PCDD} / \mathrm{Fs}$ 自体の塩化速度より十分速い。

2 ) すすや未燃炭素などの分解に伴って PCDD/Fs が生成 する経路は，前駆物質から生成する経路より燃焼反応 の影響を強く受ける。

上記のすすや未燃炭素などの分解に伴って PCDD/Fs が生 成する際の塩化速度という表現は，すすや未燃炭素などの分 解により PCDD/Fs の炭素骨格が作られる過程で, その炭素

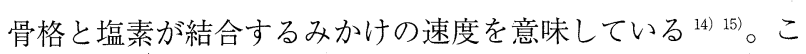
れらの仮定の上で考えると，PCDDs，PCDFs ともに両方の反 応経路が関与しているが，PCDDs は主に前駆物質を経由して 生成し, PCDFs は主にすすや未燃炭素などの分解に伴って生 成したと考えると，今回の実験結果をうまく説明できる。塩 化速度が速い前駆物質経由による生成割合の多い PCDDs は, PCDFs に比べて塩素化が進んだ結果となる。また，すすや未 燃炭素などの分解に伴って生成する割合の多いPCDFs は，炉 内の燃焼反応の変化によって, 同族体分布や生成量の変化が PCDDs より大きくなる。このことは，すすや未燃炭素などが 多く生成するほど，これらの分解に伴って生成する PCDFs の 割合も多くなることを意味している。
排ガスの CO 濃度の上昇と $\mathrm{PCDD} / \mathrm{Fs}$ 生成量の増大に伴って 同族体分布が高塩化物側に移行した原因については，燃焼反 応に打ける塩素の挙動が強く影響していると考えられるが, 本実験結果から反応の詳細を議論することはできない。

\section{4. 結 言}

外熱式の小型流動層実験装置を用いて模擬ゴミの燃焼実験 を行い，廃棄物に含まれる塩素量と燃焼室の温度が排ガス中 $\mathrm{PCDD} / \mathrm{Fs}$ の同族体分布に与える影響を明らかにした。本実験 条件下では, PCDDsの方が高塩化物の割合が多く, PCDFsに 比べて塩素化が進んでいた。また，排ガスのCO 濃度が増え ると PCDDs, PCDFs ともに生成量が増加するが，この時それ ぞれの同族体分布は高塩化物側に移行した。この生成量と同 族体分布の変化は PCDFs の方が PCDDs に比べて大きかった。

さらに，本実験で得られた同族体分布の挙動を説明できる $\mathrm{PCDD} / \mathrm{Fs}$ の生成経路について考察した。PCDDs と PCDFs で は主要な反応経路が異なっており, PCDDs は塩化速度が速い 物質を経由して生成し, PCDFs の生成経路は燃焼反応の影響 を強く受けると推測した。

\section{文 献：References}

1 ) Addink, R., Olie, K., Environ. Sci. Technol, 29, 1425 (1995)

2 ) Tuppurainen, K., Halonen, I., Ruokojarvi, P., Tarhanen, J., Ruuskanen, J., Chemosphere, 36, 1493 (1998)

3 ) Mattila, H., Virtanen, T., Vartiainen, T., Ruuskanen, J., Chemosphere, 25, 1599 (1992)

4) 畑中健志, 今川隆, 竹内正雄, 燃焼の科学と技術, 8, 163 (2001)

5 ) Addink, R., Bavel, B. V., Visser, R., Wever, H., Slot, P., Olie, K., Chemosphere, 20, 1929 (1990)

6 ) Gullett, B. K., Bruce, K. R., Beach, L. O., Chemosphere, 20, 1945 (1990)

7 ) Stieglitz, L., Zwick, G., Beck, J., Roth, W., Vogg, H., Chemosphere, 18, 1219 (1989)

8 ) Watanabe, T., Asai, M., Kondo, T., Shimizu, M., Takeuchi, Y., Aramaki, H., Naito, M., Chemosphere, 32, 177 (1996)

9 ) Wikstrom, E., Tysklind, M., Marklund, S., Environ. Sci. Technol., 33, 4263 (1999)

10) Imagawa, T., Takeuchi, M., Organohalogen Compounds, 23, 487 (1995)

11) Hatanaka, T., Imagawa, T., Takeuchi, M., Environ. Sci. Technol., 34, 3920 (2000)

12) Hatanaka, T., Imagawa, T., Kitajima, A., Takeuchi, M., Environ. Sci. Technol., 35, 4936 (2001)

13）竹内正雄, 日工六誌, 80, 278 (2001): Takeuchi, M., J. Jpn. Inst. Energy, 80, 278(2001)

14) Ino, F., Imagawa, T., Takeuchi, M., Sadakata, M., Environ. Sci. Technol., 33, 1038 (1999)

15) Hatanaka, T., Imagawa, T., Takeuchi, M., Chemosphere, 46, 393 (2001) 